\title{
An analysis of the direct cost of renal dialysis provided through a public-private partnership at a tertiary hospital in Limpopo Province, South Africa
}

\author{
T A Malatji, MB ChB FCPHM; J T Wamukuo, BSc, MSc (HEcon), DHSM; \\ F L M Hyera, MD, PGDip (ObGyn), DTM\&H, DOM\&H, MSc (Community Health), MMed (Community Health)
}

Department of Public Health Medicine, Faculty of Health Sciences, University of Limpopo, Mankweng, South Africa

Corresponding author: T A Malatji (tumimalatji79@gmail.com)

\begin{abstract}
Background. Chronic kidney disease (CKD) is increasingly recognised as an important cause of morbidity and mortality in South Africa (SA). Although the cost of dialysis is well documented in developed countries, little is known about this cost in sub-Saharan Africa.

Objectives. To review the costs of providing peritoneal dialysis (PD) and haemodialysis (HD) at the Pietersburg renal dialysis public-private partnership (PPP) unit in Limpopo Province, SA.

Methods. A retrospective review of the cost of inputs required for HD and PD was conducted from a provider's perspective, covering the period 2007 - 2012. A top-down approach was used to estimate the average annual cost per patient on HD and PD.

Results. During the 6-year period under review, the number of patients on dialysis increased from 77 in 2007 to 182 in 2012. More than $60 \%$ of the patients were on HD. The average annual cost per patient was estimated to be ZAR212 286 (USD25 888) and ZAR255 076 (USD31 106) for HD and PD, respectively, in 2012. Personnel cost, PD supplies, HD supplies, the outsourcing fee and pharmaceutical supplies were the main cost drivers. PD proved to be more expensive than HD, despite the use of locally manufactured fluids.

Conclusions. The study highlights the exceptionally high cost of dialysis treatment. Dialysis should be made more accessible by implementing measures to address the main cost drivers. Moreover, a comprehensive approach that includes prevention of CKD at primary healthcare level, an organ donation programme and an effective kidney transplant programme is urgently required in Limpopo. Further research is required to evaluate the cost-effectiveness of the PPP approach.
\end{abstract}

S Afr Med J 2019;109(8):577-581. DOI:10.7196/SAMJ.2019.v109i8.13597

Chronic kidney disease (CKD) and end-stage renal disease (ESRD) are important causes of morbidity and mortality in South Africa (SA). The close link between CKD and the growing burden of non-communicable diseases further underscores the importance of $\mathrm{CKD}$. Although renal replacement therapy in the form of dialysis is a life-saving treatment, access to dialysis in the SA public sector has remained largely unchanged since the advent of democracy. ${ }^{[1]}$ The situation is worse in rural provinces such as Limpopo, where there is only one dialysis centre in the public sector. Renal failure is reported to be among the top 10 causes of natural deaths in Limpopo. ${ }^{[2]}$ The cost of dialysis is a key factor preventing access to it. There is therefore a need to identify strategies to make dialysis more accessible and cost-effective.

The National Department of Health convened a summit in 2015 to discuss the challenges posed by CKD in SA and propose solutions. ${ }^{[3]}$ The meeting recommended a call to increase the dialysis rate from 164 to 250 per million population (pmp) by $2025 .{ }^{[3]}$ The use of private-public partnerships (PPPs) was among the strategies proposed to achieve the target figure. National Treasury defines a PPP as an agreement between the public and private sectors where the private sector is contracted to perform an institutional function on behalf of the public sector in return for a benefit. ${ }^{[4]}$ The Pietersburg Hospital dialysis unit in the city of Polokwane is the first and only renal dialysis unit in the public health sector in Limpopo, and the only PPP renal unit in SA. It is important to explore the cost implications of using the PPP approach for the provision of renal dialysis services.

Few detailed costing studies on renal dialysis have been conducted in sub-Saharan Africa. ${ }^{[5]}$ In 2010, Abu-Aisha et al..$^{[6]}$ estimated the annual cost of dialysis per patient in SA to be USD12 000 and USD7 000 for peritoneal dialysis (PD) and haemodialysis (HD), respectively ${ }^{[6]}$ A survey of renal replacement in Africa, conducted using interviews with key informants in 2007, estimated the annual cost of HD and PD to be USD20 000 and USD30 000, respectively. ${ }^{[7]}$ These cost estimates omitted details of the costing approach and the cost components included. More detailed cost studies will provide the full cost of dialysis and identify the cost drivers.

\section{Objectives}

To estimate the direct cost of providing PD and HD using the PPP approach at the PPP dialysis unit in Polokwane.

\section{Methods}

The study was conducted at Pietersburg Hospital, a 500-bed tertiary institution in Polokwane. Together with Mankweng Hospital, Pietersburg Hospital is responsible for providing tertiary services to the population of Limpopo. Limpopo is a mostly rural province with an estimated population of 5.8 million spread across five districts. ${ }^{[8]}$ The renal dialysis unit at Pietersburg Hospital is the only dialysis centre for an estimated 5.3 million uninsured individuals who depend on the public health sector. ${ }^{[8]}$

Prior to 2006, chronic dialysis patients were referred to Dr George Mukhari Hospital in Pretoria for dialysis treatments. The Limpopo Provincial Department of Health $(\mathrm{LDoH})$ and a private partner signed a PPP agreement for a 10-year period (2006 - 2016), thereby establishing the Pietersburg renal dialysis unit. The $\mathrm{LDoH}$ pays a monthly reimbursement fee to the private partner for the capital cost 
and services provided by the private partner as stipulated in the PPP contractual agreement. The renal dialysis unit provides in-centre HD and chronic ambulatory PD to public sector patients from across the province. In accordance with other public sector dialysis units, strict exclusion criteria are applied when selecting patients for dialysis. ${ }^{[9]}$

A retrospective cost analysis was conducted covering the period $2007-2012$ at the renal dialysis unit. The analysis was conducted from the service provider's perspective. A renal doctor and nurse were consulted in order to identify the principal resources required to provide $\mathrm{HD}$ and $\mathrm{PD}$. The main resources identified included both variable (pharmaceuticals and material supplies) and quasifixed (personnel, equipment, utilities and buildings) items. The cost data were sourced from both the private partner's annual audited expenditure statements and the hospital's pharmacy, finance and human resources departments. All costs were calculated in South African rands (ZAR). Table 1 describes the private and public sector key cost parameters and the data sources.

\section{Inclusion and exclusion factors}

Since the cost analysis was conducted from the provider's perspective, the indirect costs (incurred 'privately' by the patients) to access the dialysis unit were not included. The study also excluded the costs associated with surgical interventions, HD patients' access creation, PD patients' abdominal catheter procedures, and hospital admissions.

\section{Data analysis}

The derived cost and patient data were captured and analysed using Excel version 2010 (Microsoft, USA). The data collected were cleaned and necessary follow-ups were made for validation in the case of errors and/or outliers before estimating total and unit costs. For all the annual cost estimates, a discount rate of $4 \%$ was applied to account for the devaluation of cost over time.

Some of the cost components were available only in aggregated totals for both dialysis modalities. These included capital cost, human resources, laboratory tests, blood transfusions, pharmaceutical items,

Table 1. Cost components and data collection methods (2007 - 2012)

\begin{tabular}{|c|c|}
\hline Cost components & Data collection methods and data sources \\
\hline \multicolumn{2}{|l|}{ Private partner inputs } \\
\hline \multicolumn{2}{|l|}{ Capital costs } \\
\hline Building cost & The private partner's annual expenditure records contained all the capital costs for the \\
\hline HD machines & project from 2007 to 2012 . The buildings were annualised over a period of 30 years. The \\
\hline Dialysis chairs & other capital costs were annualised over the lifespan of the goods, which was $\sim 10$ years. \\
\hline \multicolumn{2}{|l|}{ Water purification system } \\
\hline \multicolumn{2}{|l|}{ Recurrent costs } \\
\hline Private partner personnel & $\begin{array}{l}\text { The private partner provided information on the gross salaries of their employees. This } \\
\text { included all nursing staff, two clinical technicians, sessional staff and a unit manager. }\end{array}$ \\
\hline Other recurrent costs & $\begin{array}{l}\text { The private partner records were used to identify other indirect recurrent costs. These } \\
\text { covered electricity, water, cleaning services, laundry facilities, catering and administration. }\end{array}$ \\
\hline HD supplies & $\begin{array}{l}\text { The annual cost of HD supplies, which included dialysers, blood line set and other medical } \\
\text { supplies, was determined from the private partner's annual audited expenditure records. }\end{array}$ \\
\hline
\end{tabular}

Public sector inputs

Recurrent costs

Public sector personnel

The hospital's human resources department provided personnel salary cost information. These included a staff nurse, a medical clerk and medical doctors. The overtime cost for the medical officers was excluded.

Pharmaceutical items

The pharmacy department provided cost data on ward stock supplied to the renal unit. The data included all oral and intravenous medication, as well as medical supplies including renal catheters and PD catheters.

Laboratory tests

The NHLS provided monthly costs of all laboratory investigations tests ordered by the renal unit.

Blood products

The SANBS provided cost data on blood transfusion and related products ordered by the renal unit.

PD supplies

The annual PD supplies costs, which included PD fluids, disinfection caps and connecting lines, were determined from hospital invoices to suppliers. The cost of the PD supplies also included transporting supplies to patients' homes.

Utilisation data

Number of patients on chronic HD and PD

The renal dialysis unit provided statistics on the average annual number of patients on chronic HD and PD.

Outsourcing fee

Reimbursement amount

The annual reimbursement amount, which is the amount the public sector pays to the private partner, was collected from annual audited hospital expenditure reports. The reimbursement amount was based on the number of HD sessions per month, which were charged at an agreed-upon rate as stipulated in the PPP agreement with annual inflation.

Outsourcing fee The annual outsourcing fee, which represents the additional cost of the PPP approach, was calculated by subtracting the total annual cost of private partner inputs from the annual reimbursement amount.

$\mathrm{HD}=$ haemodialysis; $\mathrm{PD}$ = peritoneal dialysis; $\mathrm{NHLS}$ = National Health Laboratory Service; SANBS = South African National Blood Service; PPP = public-private partnership. 
laundry, cleaning and catering and other recurrent costs. To estimate the total cost of treating either HD or PD patients, these aggregate costs were apportioned to each service using allocation criteria that reflect actual resource usage. The standard operating procedures and the dialysis guidelines primarily informed the allocation of shared costs to HD and PD. Overall, we made the following assumptions in disaggregating these costs:

- HD patients are mostly hospital-based and are required to dialyse for 4 hours, three times a week. They therefore require 12 visits to the renal unit per month.

- PD is mostly done at home, with a single monthly visit to the renal unit.

- All patients are on a 6-week acute HD programme before being assigned to a dialysis modality.

- The standard procedures for HD and PD in terms of blood transfusions and routine laboratory investigations are similar for both dialysis modalities.

- The requirement for intravenous medical supplies is greater for HD patients than for those on PD because of their frequent visits to the dialysis unit and the nature of the dialysis.

\section{Unit cost estimation}

A top-down approach was used to arrive at an estimated cost per patient (unit costs) for HD and PD. The total annual cost for both HD and $\mathrm{PD}$ was divided by the annual number of patients on chronic $\mathrm{HD}$ and PD, respectively, to determine unit costs for each of the 6 years. The unit costs for 2012 were converted to US dollars (USD) using the official World Bank 2012 exchange rate, which was on average $1 \mathrm{USD}=8.2 \mathrm{ZAR}$ (in December 2012) to allow for comparison. ${ }^{[10]}$

\section{Sensitivity analysis}

A sensitivity analysis was conducted to test the robustness of the estimates by varying the allocation percentage for PD supplies, HD supplies, pharmaceutical items and personnel, which contributed $>70 \%$ to the total cost in any given year. The uncertainty was limited to personnel cost and the cost of pharmaceutical supplies, which were apportioned to $\mathrm{PD}$ and $\mathrm{HD}$ according to the key assumptions described above. The varying of the allocation percentages for personnel costs and pharmaceutical items cost by $20 \%$ did not impact significantly on the overall unit costs estimated for PD and HD.

\section{Ethical considerations}

Ethical approval was obtained from the Medunsa Research and Ethics Committee at the University of Limpopo, now Sefako Makgatho Health Sciences University (ref. no. MREC/M/164/2014).

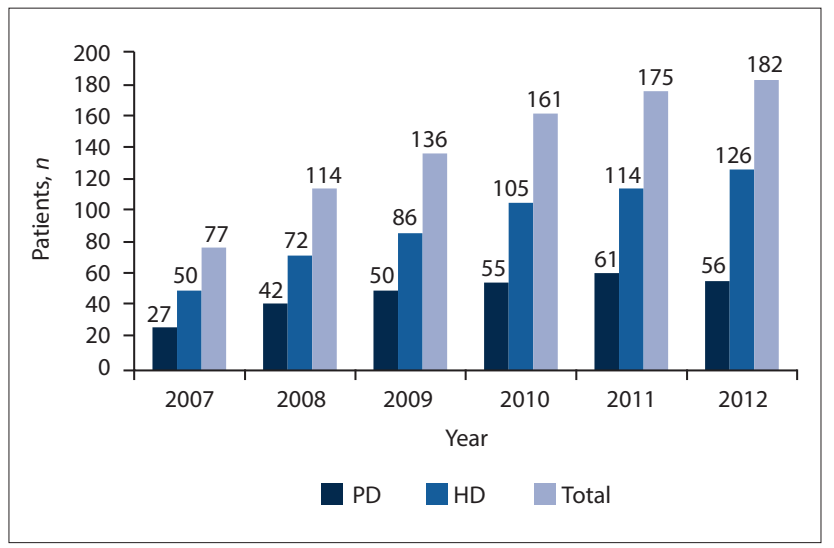

Fig. 1. Number of patients on PD and HD (2007 - 2012). (PD = peritoneal dialysis; $H D=$ haemodialysis.)

\section{Results}

The number of patients on dialysis increased from 77 in 2007 to 182 in 2012 (Fig. 1). More than $60 \%$ of the patients were on HD.

The total cost of providing PD and HD between 2007 and 2012 was ZAR174 167572 (before discounting). The major cost drivers were personnel (24\%), PD supplies (18\%), HD supplies (16\%), the outsourcing fee (12\%) and pharmaceutical supplies (11\%) (Table 2). In combination, these items accounted for $81 \%$ of the total cost.

The annual cost per patient for HD fluctuated between ZAR180 213 and ZAR215 374 (Table 3), whereas that for PD ranged between ZAR228 414 and ZAR264 658. The HD/PD ratio was estimated to be 0.83 in 2012 .

\section{Discussion}

Given that the Pietersburg Hospital renal dialysis unit is the only public health sector dialysis unit in Limpopo, it is not surprising that the number of patients on dialysis more than doubled between 2007 and 2012. Despite the increase in the number of dialysis patients highlighted in this study, access to dialysis remains severely limited in Limpopo, with an estimated dialysis prevalence of $59 \mathrm{pmp}$ in contrast to an average of $189 \mathrm{pmp}$ for SA. ${ }^{[1]}$

HD was the dominant mode of dialysis, with $69.2 \%$ of patients on HD in 2012. Similarly, Okpechi et al. ${ }^{[11]}$ estimated a PD proportion of $28 \%$ for SA, ${ }^{[11]}$ which is higher than the estimated global average of $11 \% \cdot{ }^{[12]}$ With few exceptions, the PD proportion in African countries is low; the figures for Egypt, Morocco, Tunisia and Kenya were estimated to be $0.14 \%, 0.62 \%, 3.0 \%$ and $10 \%$, respectively. ${ }^{[1]}$ In less developed countries, poor social circumstances, the cost of PD solutions, lack of access to clean water and inadequate sanitation hinder the use of PD. ${ }^{[1]}$

Despite the rationing of dialysis in the public sector, provision of dialysis is expensive. The total dialysis cost for $\sim 200$ patients in 2012 was almost ZAR40 million, which used $4.4 \%$ of the hospital's total budget. In developed countries, it is estimated that $2-3 \%$ of health expenditure is spent on treatment for patients with ESRD, although they account for a small proportion of the total population. ${ }^{[13]}$ Dialysis treatment demands a significant portion of scarce financial resources while benefiting only a few patients.

Measures to curb the cost of dialysis should be directed at the main cost drivers. Personnel cost, PD supplies, HD supplies, the outsourcing fee and pharmaceutical supplies were the main cost drivers in our study, accounting for $81 \%$ of the total dialysis cost. This finding concurs with previous studies in which recurrent costs as opposed to capital expenditure were reported to be the main cost driver. ${ }^{[14]}$ Decision-makers should explore various strategies to reduce the cost of dialysis supplies. For instance, the re-use of dialysers, price negotiations and reducing import duty taxes for dialysis supplies have been proposed as cost-reduction strategies. ${ }^{[3]}$ In terms of the personnel cost, the national renal summit proposed a reduction of the professional nurse-to-patient ratio from the current 1:4 to $1: 6$, coupled with an introduction of a mid-category worker (task shifting). ${ }^{[3]}$ Cautious implementation of cost-cutting measures is necessary to safeguard the quality of dialysis.

In 2012, the average annual unit costs per patient on HD and PD were estimated to be ZAR212 286 (USD25 888) and ZAR255 076 (USD31 106), respectively. These figures are higher than the USD12 000 and USD7 000 for PD and HD, respectively, reported by Abu Aisha et al..$^{[6]}$ in 2010. El Matri in 2008 estimated the annual cost of HD and PD in SA to be USD20 000 and USD30 000, respectively. ${ }^{[7]}$ Comparison between the various estimates for SA is limited by the fact that costing approaches and cost items included were not stated in the previous studies. The outsourcing fee, which represents 
the cost of the PPP approach, contributed $12 \%$ to the total cost in the present study, and may have contributed to the higher cost estimates.

Given the differences in health systems, approaches to costing, management protocols, currencies and timing of studies, the comparison of raw cost data across countries is considered to be complex $\cdot{ }^{[14]}$ However, it is useful to compare costs between countries of similar economic development and location. In a systematic review, Mushi et al.$^{[5]}$ reported the cost of dialysis in low- and middle-income countries. Cost-analysis studies in Chile and Brazil estimated the annual cost of HD from a societal perspective to be USD24 461 and USD30 079, respectively, and that of PD to be USD24 389 and USD28 592. ${ }^{[5]}$ The annual cost of HD in African countries ranged from USD16 000 in Kenya to USD24 500 in Namibia, USD27 440 in Tanzania and USD42 784 in Nigeria; the annual cost of PD was USD12 000 in Kenya, USD24 500 in Namibia and USD47 970 in Nigeria. ${ }^{[5]}$ The annual cost of PD in the present study was higher than most of the estimates from other countries, with the exception of Nigeria.

Differences between the unit cost for HD and PD and patient costs for other services in the health system are worth noting. For instance, the annual unit cost for HD and PD is substantially higher than the average annual cost per patient-day equivalent at Pietersburg Hospital, which was calculated at ZAR13 684 in 2012. Similarly, the unit cost for HD and PD is significantly higher than the average annual unit cost of providing HIV treatment in a public

Table 2. Cumulative total cost of running the renal dialysis PPP project $(2007-2012)$

\begin{tabular}{lll}
\hline Item & Cumulative cost (ZAR) & $\%$ \\
\hline Personnel & 40802514 & 24 \\
PD supplies & 30974410 & 18 \\
HD supplies & 27754244 & 16 \\
Outsourcing fee & 20258609 & 12 \\
Pharmaceutical supplies & 18320189 & 11 \\
NHLS (laboratory tests) & 8188262 & 5 \\
Maintenance & 6847342 & 4 \\
Capital items & 5996741 & 4 \\
Administration & 3052160 & 2 \\
Catering & 2202654 & 1 \\
Other recurrent costs & 1777755 & 1 \\
Blood products & 1766444 & 1 \\
Cleaning services & 1427368 & 1 \\
Laundry services & 451309 & 0,3 \\
Grand total & 169820001 & 100 \\
PPP = public-private partnership; PD = peritoneal dialysis; HD = haemodialysis; &
\end{tabular}

sector institution, which was estimated at ZAR8 705.18 (USD682.2) in 2011. ${ }^{[15]}$

The HD/PD cost ratio (the annual cost per HD patient divided by the annual cost per PD patient) has been proposed to compare annual cost per patient on the two types of dialysis. ${ }^{\left[{ }^{14]}\right.}$ Despite the use of locally manufactured PD fluids, the annual cost of PD per patient was greater than that of $\mathrm{HD}$ in any given year, with an $\mathrm{HD} / \mathrm{PD}$ ratio of 0.83 in 2012. This is consistent with previous studies, in which $\mathrm{PD}$ was more expensive than HD in most developing countries. ${ }^{[16]}$ The use of imported PD fluids is commonly cited as the main reason for the high PD cost in developing countries. ${ }^{[16]}$ In contrast, we confirmed that the PD fluids used in the Pietersburg renal unit were locally produced. The additional cost of transporting PD supplies across a rural province may have contributed to the high cost of PD v. HD.

The PPP approach is proposed as one strategy to increase access to dialysis. The outsourcing fee, which represents the additional cost of providing dialysis service through the partnership, was identified as one of the cost drivers in this study. The outsourcing fee was estimated to be ZAR20.259 million over 6 years, representing 11\% of the total cost. It is difficult to make a judgement on the additional cost of the PPP approach, because there is no stipulated agreement on the national benchmark or standard for the additional costs attached to the partnership approach. Furthermore, according to National Treasury, the value-for-money criterion, which states that the provision of institutional function by a private partner should result in net benefit in terms of cost, price, quality, quantity and risk transfer', is recommended for evaluating the PPP approach. ${ }^{[4]}$ The risks and benefits of the PPP v. the public sector approach should therefore also be measured to comprehensively evaluate the value of the partnership.

\section{Study limitations}

This study is not without limitations. The health provider's perspective, which considers the direct cost of dialysis provision, was used to estimate the cost of dialysis in this study. Because HD is conducted at the hospital facility three times a week, by excluding its indirect costs the expenditure on HD may be underestimated. The dialysis patients in this study were selected using strict criteria that prioritised younger patients with less comorbidity; the estimates of dialysis cost will therefore apply to such a population. The study was conducted more than 6 years ago, so it is possible that the situation may have changed since 2012. However, the study is still useful for health planners because it provides a baseline assessment that outlines the costing approach and the cost components included. The fact that the study was conducted in a context of a PPP further underscores its importance in the era of universal health coverage.

Table 3. Annual unit cost of HD and PD (2007 - 2012)

\begin{tabular}{|c|c|c|c|c|c|c|c|}
\hline \multirow[b]{2}{*}{ Year } & \multicolumn{3}{|c|}{ Unit cost for HD (ZAR) } & \multicolumn{3}{|c|}{ Unit cost for PD (ZAR) } & \multirow[b]{2}{*}{$\begin{array}{l}\mathrm{HD} / \mathrm{PD} \\
\text { ratio }\end{array}$} \\
\hline & $\begin{array}{l}\text { Total annual } \\
\text { cost for HD }\end{array}$ & HD patients, $n$ & Cost per HD patient & $\begin{array}{l}\text { Total annual cost } \\
\text { for PD }\end{array}$ & PD patients, $n$ & Cost per PD patient & \\
\hline 2007 & 10768706 & 50 & 215374 & 7145775 & 27 & 264658 & 0.81 \\
\hline 2008 & 13690004 & 72 & 190139 & 9593388 & 42 & 228414 & 0.83 \\
\hline 2009 & 16827559 & 86 & 195669 & 11578889 & 50 & 231578 & 0.84 \\
\hline 2010 & 18922398 & 105 & 180213 & 12685071 & 55 & 230638 & 0.78 \\
\hline 2011 & 23877183 & 114 & 209449 & 14414562 & 61 & 236304 & 0.89 \\
\hline 2012 & 26748015 & 126 & 212286 & 14284251 & 56 & 255076 & 0.83 \\
\hline
\end{tabular}




\section{Conclusions}

The provision of dialysis for patients with ESRD is a large economic burden for the health system. In this study we estimated the annual cost for HD and PD in 2012 to be ZAR212 286 (USD25 888) and ZAR255 076 (USD31 106) per patient, respectively. Despite the fact that PD is considered a less resource-intensive dialysis therapy than HD, the annual PD cost was greater than that of HD in any given year. In order to improve efficiency of dialysis, we should prioritise measures to mitigate the main cost drivers, which included personnel cost, PD supplies, HD supplies, the outsourcing fee and pharmaceutical supplies. Furthermore, it is imperative to develop a comprehensive primary healthcare-based approach to preventing $\mathrm{CKD}$. The value of methodologically sound costing studies to inform policy on the prevention and management of CKD in developing countries cannot be over-emphasised.

\section{Declaration. None.}

\section{Acknowledgements. None.}

Author contributions. TAM drafted the article, JTW analysed the cost data spreadsheet and drafted the methodology, and FLMH reviewed the article and finalised the discussion.

Funding. None.

Conflicts of interest. None.
2. Statistics South Africa. Mortality and causes of death in South Africa, 2016: Findings from death notification. Statistical release P0309.3. Pretoria: Stats SA, 2018. http://www.statssa.gov.za/ publications/P03093/P030932016.pdf (accessed 21 June 2019).

3. Moosa MR, Meyers AM, Gottlich E, Naicker S. An effective approach to chronic kidney disease in South Africa. S Afr Med J 2016;106(2):156-159. https://doi.org/10.7196/SAMJ.2016.v106i2.9928

4. National Treasury, Republic of South Africa. Public Private Partnership Manual. Pretoria: Nationa Treasury PPP Unit, 2004. http://www.ppp.gov.za/Legal\%20Aspects/PPP\%20Manual/Module\%2004 pdf (accessed 26 June 2019).

5. Mushi L, Marschall P, Fleßa S. The cost of dialysis in low and middle-income countries: A systematic review. BMC Health Serv Res 2015;15(1):506. https://doi.org/10.1186/s12913-015-1166-8

6. Abu-Aisha H, Elamin S. Peritoneal dialysis in Africa. Perit Dial Int 2010;30(1):23-28. https://doi. org $/ 10.3747 /$ pdi.2008.00226

7. El Matri A, Elhassan E, Abu-Aisha H. Renal replacement therapy resources in Africa. Arab J Nephrol Transplant 2008;1(1):9-14. https://doi.org/10.4314/ajnt.v1i1.58814

8. Statistics South Africa. General household survey 2016. Statistical release P0318. Pretoria: Stats SA 2018. https://www.statssa.gov.za/publications/P0318/P03182016.pdf (accessed 27 August 2018).

9. National Department of Health, South Africa. Guidelines for chronic renal dialysis. 2009. http://www kznhealth.gov.za/medicine/dialysisguide.pdf (accessed 27 August 2018).

0. World Bank. Official exchange rates. 2014. http://data.worldbank.org/indicator/PA.NUS.FCRF (accessed 27 August 2019).

11. Okpechi IG, Rayner BL, Swanepoel CR. Peritoneal dialysis in Cape Town. Perit Dial Int 2012;32(3):254260. https://doi.org/10.3747/pdi.2011.00100

12. Jain AK, Blake P, Cordy P, Garg AX. Global trends in rates of peritoneal dialysis. J Am Soc Nephrol 2012;23(3):533-544. https://doi.org/10.1681/asn.2011060607

13. Schieppati A, Remuzzi G. Chronic renal diseases as a public health problem: Epidemiology, social, and economic implications. Kidney Int Suppl 2005;68(98):S7-S10. https://doi.org/10.1111/j.15231755.2005.09801.x

14. Just PM, Riella, MC, Tschosik AE, et al. Economic evaluation of dialysis treatment modalities. Health Policy 2008;86(2-3):163-180. https://doi.org/10.1016/j.healthpol.2007.12.004

15. Tagar E, Sundaram M, Condliffe K, et al. Multi-country analysis of treatment cost for HIV and AIDS (MATCH): Facility-level ART unit cost analysis in Ethiopia, Malawi, Rwanda, South Africa and Zambia. PLoS One 2014;9(11):e108304. https://doi.org/10.1371/journal.pone.0108304

16. Karopadi AN, Mason G, Rettore E, Ronco C. Cost of peritoneal dialysis and haemodialysis across the world. Nephrol Dial Transplant 2013;28(10):2553-2569. https://doi.org/10.1093/ndt/gft214
worl
1. Davids MR, Marais N, Jacobs JC. South African Renal Registry Annual Report 2015. Afr J Nephrol 2017;20(1):201-213. https://doi.org/10.21804/20-1-2583
Accepted 5 February 2019. 